\title{
O Brejo das Almas de \\ Drummond: uma modernidade entre Deus e o diabo*
}

Vivaldo Santos I Georgetown University - USA

\begin{abstract}
Resumo: Olivro Brejo das Almas (1934) de Carlos Drummond de Andrade ocupa um lugar marginal dentro da crítica drummondiana, sobretudo diante da notada centralização no elemento subjetivo. Na maioria das vezes a crítica o caracteriza como simples extensão da subjetividade lírica instituida em Alguma poesia, ou ponto de transição entre a poesia irônica e individualista da chamada primeira fase drummodiana, e a poesia socialmente comprometida para a qual Sentimento do mundo (1940) acena. Pouca atenção tem sido prestada à particularidade poética de Brejo das Almas. A hipótese aqui desenvolvida é a de que o tom decadente, niilista, e dionisíaco que se vê refletido no plano temático e no plano da linguagem na constituição da subjetividade neste poemário aponta para um diálogo de Drummond com o discurso da modernidade, principalmente com respeito ao "Desencantamento do Mundo" diante da chamada "Morte de Deus."

Palavras-chave: modernidade, linguagem, desencanto.
\end{abstract}

livro Brejo das Almas (1934) de Carlos Drummond de Andrade ocupa uma posição um tanto quanto marginal dentro do conjunto da obra do poeta mineiro. Uma explicação para isso talvez seja dada à espécie de dissonância

* Este artigo é parte de um estudo maior, ainda em progresso, sobre a representação do corpo na poesia de Carlos Drummond de Andrade. Uma versão reduzida do artigo foi apresentada no VI Congresso Internacional da Brazilian Studies Association (BRASA) na cidade de Atlanta, em abril de 2002. 
do livro com o espírito do chamado high modernism, para o qual Drummond em 1930 acenou com o coloquialismo, a ironia, o humor característicos de Alguma poesia, livro que oficializa a sua entrada no cenário do modernismo brasileiro. Como entender a recaída excessiva no individualismo que Brejo das Almas propõe em pleno auge de consolidação modernista quando a chamada nova sensiblidade dava como assegurada a completa despersonalização lírica? Como entender o ranço decadente, de fin-de-siècle, que exala desse poemário brejeiro? Esta espécie de digressão que caracteriza Brejo das Almas não estaria colocando uma pedra no caminho da periodização literária, ao pôr em questão a noção evolutiva do discurso literário? Qual seria então o paradigma de leitura de Brejo das Almas?

Diante destas indagações, proponho-me neste artigo resgatar a importância de Brejo das Almas na produção poética de Drummond. O meu propósito é examinar o poemário de 1934 à luz do discurso filosófico da modernidade, pois acredito que Brejo das Almas apresenta o que há de mais visível em Drummond com respeito ao "Desencantamento do Mundo." O ideal de excesso, de intoxicação, e de exaustão física do corpo que atravessa o poemário não só explica a relação do poeta com o discurso nascido da perda do ideal de transcendência, diante da chamada "Morte de Deus," como também explica a sua aceitação (relativa) do mundo terreno, traduzido aqui no tempo presente, histórico, que norteará Sentimendo do mundo (1940) e A rosa do povo (1945).

\section{O lugar de Brejo das Almas}

Há certa dificuldade por parte da crítica em situar o livro Brejo das Almas dentro do conjunto da obra drummondiana, às vezes por caracterizá-lo como mera extensão de Alguma poesia, ou para marcar a transição entre uma poesia irônica, individualista, e uma poesia socialmente comprometida, iniciada com a publicação de Sentimento do mundo em 1940. A posição aparentemente secundária que Brejo das Almas acaba por ofuscar a importância do livro e sua particularidade poética. Indubitavelmente ainda prevalecem em Brejo das Almas traços da subjetividade presentes no primeiro livro, sobretudo a notada centralização no sujeito lírico. Contudo, o que chama a atenção do leitor nessa coletânea de poemas é o sentido de crise que se vê refletido no plano temático

1. FRIEDRICH, 1991. 
e no plano da linguagem na constituição dessa nova individualidade. ${ }^{2}$ Crise que surge a partir da constatação da precariedade da existência, e conseqüentemente imprime certo caráter de urgência na subjetividade lírica. ${ }^{3}$ A consciência da precariedade, a urgência, o niilismo e a apologia do erótico que organizam a poética de Brejo das Almas remetem de algum modo ao projeto de modernidade, sobretudo à ausência de Deus na sociedade moderna e sua substituição por um modo de saber racional, com um conseqüente ruir da idealidade.

Tratar da subjetividade drummondiana em Brejo das Almas requer certo cuidado quando comparada a Alguma poesia no modo singular de constituir-se. Enquanto o primeiro livro traz a marca do individualismo irônico, projetando uma posição distanciada desse sujeito e a realidade na qual ele se inscreve, decerto o que se verifica em Brejo das Almas é a intensificação dessa individualidade numa espécie de potencialização do eu diante da impossibilidade de transcendência, o que leva o sujeito a uma espécie de saturação do elemento humano, chegando a um desejo de intoxicação do corpo como resposta possível à constatação da sua precariedade. Ocorre, assim, uma exaltação exaustiva do corpo, na qual a existência é cantada de forma absoluta numa concepção de tempo percebida a partir do presente do corpo físico, capaz por si de superar o niilismo temático aparente.

É necessário, contudo, salientar a relação particular que o sujeito drummondiano tem com a modernidade. Embora o niilismo seja característica do sujeito moderno como um reflexo do processo de racionalização iniciado na Europa a partir do século XVII e intensificado a partir do século XIX no que veio a chamar-se Desencantamento do Mundo, não é menos tensa ou absoluta a relação do sujeito drummondiano com a questão. ${ }^{4}$ Como veremos nas análises

2. Mais do que buscar entender o sentido desta crise dentro do contexto social da revolução de 30 e o impacto que ela possa ter tido na poética de Brejo das Almas, meu interesse é pôr ênfase no modo particular de constituição dessa subjetividade como parte do espírito de uma época, não separado de todo da realidade da qual emerge, mesmo que esta não seja a realidade local.

3. Como o próprio Drummond observa em "Autobiografia para uma Revista": "Já em Brejo das Almas (1934), alguma coisa se compôs, se organizou; o individualismo será mais exacerbado mas há também uma consciência crescente da sua precariedade e uma desaprovação tácita da conduta (ou falta de conduta) espiritual do autor." ANDRADE, 1964. p. 533.

4. HABERMAS, 1996. 
a seguir, a crise do sujeito que se revela, sobretudo no que diz respeito à espiritualidade, aponta para uma brecha no projeto de modernidade. Enquanto, por exemplo, para pensadores como Nietzsche, Heidegger, ou um poeta como Baudelaire, o Cristianismo ruiu, sem qualquer ideal de redenção, e Deus deixou de existir (como explicação única e última de toda existência e de toda moral), no caso de Drummond uma tensão subsiste: Deus ainda existe, porém é inalcançável. Não podendo transcender ao divino, o sujeito drummondiano limita-se ao mundo terreno, vivendo assim uma tensão entre o ideal de transcedência e sua impossibilidade de realização.

Um segundo elemento que chama a atenção em Brejo das Almas é o lugar que o desejo sexual funciona como parte constitutiva da subjetividade. Dentro da hipótese levantada, o desejo sexual poderia ser visto como extensão da urgência que move o sujeito. Na aparente presentificação do corpo o desejo se articula também como forma possível de superação do vazio gerado pela modernidade. Se em algum momento vislumbrava-se certo desejo de transcendência a uma realidade superior, aqui esse elemento transcendente desaparece, convertendo-se numa apologia do corpo físico enquanto potencial, intensificando-se aqui o dito "sequestro sexual" que já fora observado em Alguma poesia. ${ }^{6}$ Todavia, o desejo deixa de ser lido como uma ameaça à subjetividade, senão como parte constitutiva da mesma, ao estabelecer-se como potencialidade em frente a uma "idealidade vazia," definida assim por Friedrich. Dessa maneira, uma vez constatada a impossibilidade de transcedência, o tempo

5. A tensão interna da subjetividade drummondiana revela a problemática do projeto de modernidade dentro de uma nação periférica na qual os pressupostos de racionalidade ainda não se constituíram de forma absoluta. Daí a ambigüidade, o entrelugar do sujeito, revelando o caráter incompleto do projeto de modernidade como totalidade. Ver CANCLINI, 1989; PAZ, 1993.

6. Em Alguma poesia o desejo sexual está mediado pelo elemento grotesco, coincidindo com o corpo social, como no retrato da mesmice interiorana ("Cabaré Mineiro" ou "Sesta.") É interessante observar a epígrafe que traz essa coletânea de poemas. Brejo das Almas era o nome de um próspero lugarejo do interior de Minas cuja economia baseava-se na exportação de produtos agrícolas para Belo Horizonte. No seu "auge de progresso," a nota jornalística que serve de epígrafe justifica com isto o desejo de se mudar o nome do município para com isto afastar-se do aspecto primitivo e entrar na era do progresso. Se por um lado, o nome 'Brejo das Almas' "nada significa e nenhuma justificativa oferece," aqui deixa entrever a postura cínica de Drummond com respeito à modernidade. 
futuro deixa de existir, restando apenas o tempo presente, de tal modo que a existência passa a ter como razão de ser uma poética do desejo, ocorrendo com isto uma exaltação acentuada do presente do corpo físico.

O sentido de precariedade do sujeito se define a partir de uma poética do excesso, do corpo em desbordamento, tendo no elemento impulsivo a mola propulsora na constituição da subjetividade lírica. Em frente de que discursos esse corpo impulsivo, latejante, se constrói, se manifesta? Quais são seus pontos de tensão interna? Quais são as configurações do desejo? São estas algumas das indagações que norteiam este estudo.

II. Meu amigo, vamos xingar o corpo e tudo que é dele e que nunca será alma

Meu amigo, vamos sofrer,

vamos beber, vamos ler jornal,

vamos dizer que a vida é ruim,

meu amigo, vamos sofrer.

[...]

Vamos xingar a mulher,

que está envenenando a vida

com seus olhos e suas mãos

e o corpo que tem dois seios

e tem um embigo também.

Meu amigo, vamos xingar

o corpo e tudo que é dele

e que nunca será alma.

[...]

Este poema de certo modo dá o tom da poética que permeará toda essa coletânea de poemas: o sentido lúdico, festivo, embriagado do eu em tom de convocatória como forma possível para combater a insignificância da vida. Atos cotidianos que definem em si a existência (sofrer, beber, ler jornal, escrever, morrer) são equacionados no nível da futilidade ("qualquer besteira"). O desejo de intoxicação do sujeito é acentuado, de tal forma a constituir-se numa positividade, uma válvula de escape, diante do asco que da realidade emana. O sujeito drummondiano aproxima-se da figura dionisíaca nietzschiana construída a partir da crença na superação do vazio por meio de 
uma economia fundada na exaltação, na alegria e na satisfação do presente do corpo - alternativa possível à constatação da precariedade da existência, uma vez que Deus está morto.

O "convite triste" é, ironicamente, uma apologia do festivo. Fundase sobretudo num ideal de embriaguez que se projeta para uma destruição completa do sujeito, havendo com isso uma necessidade de intoxicação do corpo pelo excesso até chegar a um estado de alienação ou de autodestruição temporária, dado à consciência finita da condição humana: "beber, gritar e morrer, / ou quem sabe? beber apenas (...) depois vomitar e cair / e dormir." Diante da impossibilidade de transcendência, eleva-se aquilo que há de mais humano no sujeito - o corpo - chegando a um quase estado de exaustão, de esgotamento do físico.

$\mathrm{Na}$ exaltação do humano, o corpo que paradoxalmente é fundamental na construção dessa subjetividade antiépica, é ao mesmo tempo impulsionado a uma total destruição, sendo até mesmo negado. Negação que se dá não somente tendo o corpo como objeto de desejo, mas o próprio corpo, em si desejoso, tornado abjeto: "Vamos xingar a mulher, / que está envenenando a vida / com seus olhos e suas mãos / e o corpo que tem dois seios / e tem um embigo também. / Meu amigo, vamos xingar / o corpo e tudo que é dele / e que nunca será alma."

O caminho para representar essa crise se vê refletido na própria linguagem que articula o discurso niilista. A estrutura anafórica do poema colabora com o encharcamento deste sentido, dando a impressão de um transbordamento textual na poética do excesso que se vai constituindo. A repetição promove um inchamento da linguagem até o ponto em que ela se vê inflacionada, saturada, de tal forma que corpo físico e corpo textual confluem numa mesma realidade, retratando a experiência do sujeito.

Nos versos finais do poema, a aguda consciência da crise parece projetar para um beco sem saída do qual não se pode escapar nem mesmo com a morte individual, pois diante de tal escolha, subsistiriam os demais

7. NIETZSCHE, 1987. p. 7-29. Ver também neste sentido a proposta sensualista, de enlevo corporal, de MARCUSE, 1955.

8. Embora prevaleça a poética dionisíaca em Drummond, é de se notar que a relação do sujeito com a modernidade é um tanto quanto ambígua. Há uma tensão entre o completo niilismo e a crença numa possível realidade superior. Dessa forma, mesmo diante da Morte de Deus, resta quase sempre uma certa nostalgia de transcendência, como revela o poema "Coisa Miserável". 
humanos e o aparente tormento da realidade. Constatado isto, o sujeito parece aceitar a condição, restando-lhe apenas intoxicar-se até os limites: até o vômito, depuração do corpo; até o sono, suspensão temporária possível; até a vez seguinte: ironicamente, até a "Aurora":

O poeta ia bêbedo no bonde.

O dia nascia atrás dos quintais.

As pensões alegres dormiam tristíssimas.

As casas também iam bêbedas.

[...]

Entre o bonde e a árvore

dançai, meus irmãos!

Embora sem música

dançai, meus irmãos!

Os filhos estão nascendo

Com tamanha espontaneidade.

Como é maravilhoso o amor

(o amor e outros produtos).

Dançai, meus irmãos!

A morte virá depois

como um sacramento.

"Aurora" coincide na sua temática com as questões levantadas na análise do poema anterior: nos versos iniciais o amanhecer que normalmente projeta o princípio da vida, revela, paradoxalmente, o princípio do fim, i.e., da morte. Curiosamente, o estado de embriaguez, de inconsciência do sujeito, é equacionado com a inocência da criança, fazendo de ambos os únicos capazes de perceber o presente apocalíptico do mundo: "Tudo era irreparável. / Ninguém sabia que o mundo ia acabar (apenas uma criança percebeu mas ficou calada)." O estado de inconsciência desses dois sujeitos favorece a consciência da realidade, da existência e do seu fim trágico. A identificação do poeta com a criança - símbolo da sapiência inocente - serve ao mesmo tempo para distanciálo do mundo dos adultos, privilegiado ainda mais por seu estado de intoxicação. Ao fazer isto, o sujeito lírico nega todo o presente utilitário, o qual seria o próprio vir-a-ser dessa criança. Assim, qualquer ato utilitário da existência se vê esvaziado, numa gratuidade do cotidiano: "Últimos pensamentos! últimos telegramas! José, que colocava pronomes, / Helena, que amava os homens, / Sebastião, que se arruinava, / Artur, que não dizia nada, / embarcam para a eternidade." 
Porém, a condição de poeta permite ao sujeito lírico entrever uma saída possível para esse fim trágico: "O poeta está bêbedo, mas / escuta um apelo na aurora." Como se a tragicidade estivesse presente na natureza humana mais que na natureza em si, o poeta vislumbra na invocação da aurora um novo sentido da existência, recuperando com isso o significado primeiro do amanhecer como positividade. Equaciona-se com isto a natureza com o sentido lúdico da natureza humana presente na dança, na celebração festiva do corpo. A voz oracular da aurora, presente no uso da segunda pessoa do plural (vós) "dançai, meus irmãos! / Embora sem música / dançai, meus irmãos!" - passa a prometer um ideal de transcendência capaz de superar o terreno.

No poema "Aurora", o sujeito lírico embora consciente da precariedade evita a atitude niilista advinda do futuro trágico ao fazer uma apologia festiva da existência. Aqui, como em alguns poemas da obra anterior, o dramatismo da existência é minimizado. Se anteriormente existia certa gratuidade no riso irônico do sujeito lírico, ou ele estava marcado por um ceticismo advindo da inconseqüência do trágico, aqui o que se observa é a exaltação, quiçá irônica, da existência presente. A partir da inutilidade do presente, nega-se a utilidade do corpo enquanto ação pessoalizada, desfazendo-se assim numa sublimação dele, para com isso propor uma libertação da cotidianidade útil do corpo. ${ }^{9}$ O sentido apocalíptico se desfaz numa espécie de delírio carnavalizado, sublimandose nas positividades do corpo, naquilo que de lúdico e festivo a existência apresenta: a dança, o nascimento dos filhos (metonimicamente, o desejo sexual), o amor e os produtos comerciais. Seria dizer, de uma economia da re-produção. Cabe notar aqui que a promessa desse porvenir da aurora nada mais é que uma visão ironizada da modernidade, no que diz respeito à produção industrial capitalista. ${ }^{10}$ O que se encontra acentuado é a gratuidade da produção, do seu

9. Marshall Berman numa análise do modernismo em Marx diz que essa oscilação entre o niilismo e a liberação dos impulsos é algo típico do modernismo, fruto do modo econômico que se está instituindo: "o tema dos desejos e impulsos insaciáveis, da revolução permanente, do desenvolvimento infinito, da perpétua criação e renovação em todas as esferas da vida; e sua antítese radical, o tema do niilismo, da destruição insaciável, do estilhaçamento e trituração da vida, do coração das trevas, do horror. Marx mostra como ambas essas possibilidades humanas se fundem na vida de todo homem moderno, através dos movimentos e pressões da economia burguesa." BERMAN, 1996. p. 100.

10. Sobre a visão irônica de Nietzsche da modernidade, ver BERMAN, 1996. p. 22. 
sentido de acumulação. Ao excesso de produção equacionam-se os sentimentos (desejo/amor) como parte da produção de massa da sociedade moderna, materialista em si, porém rica em promover e sujeitar o indivíduo a uma pluralidade de desejos. Assim, mesmo que a aurora pareça projetar o tempo futuro, paradoxalmente o tempo que se projeta é o tempo presente, de tal forma que qualquer transcendência seria mera contigência do instante presente do corpo. Ironicamente, "a salvação possível" estaria por advir desses "presentes" possibilitados pela modernização. O futuro trágico como decadência do corpo é reconfigurado em nome de um cantar da plenitude do corpo presente, no qual a morte enquanto fim ou negatividade seria uma mera sacramentalização do corpo moderno.

Outro poema evocativo do pessimismo e do tom dionisíaco em Brejo das Almas que merece consideração é "Um Homem e o seu Carnaval":

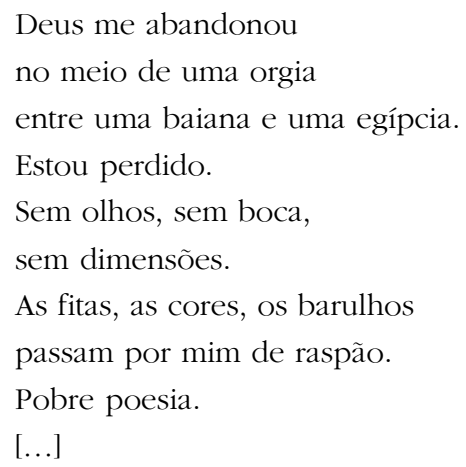

O verso inicial remete-nos de imediato a certo sujeito agônico presente no "Poema de Sete Faces" de Alguma poesia ("Meu Deus, por que me abandonaste / se sabias que eu não era Deus / se sabias que eu era fraco.") No entanto, se em Alguma poesia o sujeito lírico oscilava entre o desejo de transcedência e reconhecimento da condição precária do sujeito, aqui o dilema resolve-se na carnavalização do divino, numa maior aceitação e conseqüente exarcebação do elemento humano. Persiste ainda a presença excessiva do sujeito, sobretudo na individualização da experiência coletiva do carnaval para o entendimento da subjetividade lírica. Ironicamente, o abandono individual é projetado num espaço da coletividade, da orgia, no qual o sujeito desaparece na multidão dos corpos. A experiência do sujeito se constitui no nível do delírio. A sua consciência se articula a partir de um total apagamento de si enquanto presença física individual, a ponto de restar apenas uma sensação do corpo e da própria realidade. 
Nesse ambiente, o processo de degeneração do sujeito se intensifica e se vê refletido na própria destruição do corpo, desde o físico até os limites da linguagem que o mesmo articula. O anseio é o da destruição total e absoluta do ser. $\mathrm{O}$ indivíduo desaparece enquanto sujeito físico, projetando-se para uma completa decadência do corpo, assumindo um aspecto cadavérico, como sugere o adjetivo "lívido". Por outro lado, a linguagem vai se caracterizando pela perda da voz, pela impossiblidade de comunicação ou de articulação discursiva: "Estou lívido, gago." A fragmentação do corpo perde gradativamente sua forma, aproximando-se do esquizofrênico "corpo sem órgãos" postulado por Gilles Deleuze e Félix Guattari em Capitalismo e esquizofrenia, que buscando resistir a qualquer organicidade

presents its smooth, slippery, opaque, taut surface as a barrier. In order to resist linked, connected, and interrupted flows, it sets up a counterflow of amorphous, undifferentiated fluid. In order to resist using words composed of articulated phonetic units, it utters only gasps and cries that are sheer unarticulated blocks of sound. ${ }^{11}$

No entanto, o elemento trágico se minimiza diante do aspecto delirante do poema. O sentimento de angústia se reduz na própria aceitação do abandono divino ou mesmo na constatação da impossibilidade de realização do desejo físico, projetado na figuração metonímica do corpo feminino: "Eternas namoradas / riem de mim demonstrando os corpos, / os dentes. / Impossível perdoá-las, / sequer esquecê-las.” Ainda que esteja presente a destruição gradativa do sujeito, não há tragicidade na morte. A morte é equacionada com a experiência carnavalesca, lúdica e gozosa, colaborando o próprio corpo textual na figuração desta realidade de sonhos, de puro fluir da subjetividade, como é verificado na ruptura da linearidade da linguagem, na ausência de pontuação, na repetição dos vocábulos - nas "palavras em liberdade" que nos remetem às estéticas de vanguarda surrealista e futurista. Na última estrofe, por exemplo, o delírio do corpo físico se converte no delírio do próprio corpo textual: "Estou me afogando / peixes sulfúreos / ondas de éter / curvas curvas curvas / bandeiras de préstitos / pneus silenciosos / grandes abraços largos espaços / eternamente.”

11. DELEUZE; GUATTARI, 1983. p. 9. 


\section{A brejeirização da alma: Oh! sejamos pornográficos!}

Como já foi visto na análise dos poemas anteriores, o corpo funciona como parâmetro fundamental na constituição da subjetividade no entendimento da relação desse sujeito com a modernidade, sobretudo diante da constatação da sua impossibilidade de transcendência. No grupo de poemas que passaremos a analisar, veremos como o corpo como desejo físico ganha extremada relevância numa espécie de "brejeirização da alma." Na apologia do amor brejeiro, impudico, o que se observa, a partir de agora, é uma acentuação do elemento humano do sujeito no que diz respeito ao desejo sexual. A temática que organiza esse grupo de poemas gira em torno a uma apologia do corpo desejoso como forma constitutiva da subjetividade, convertendo-o numa potencialidade, como já vinha sendo vislumbrado no processo de intoxicação do corpo, discutido anteriormente. Contudo, se por um lado a subjetividade, no que se refere à saturação do humano, se constitui como reflexo do Desencantamento do Mundo, ao mesmo tempo ela se articula também como suposta reação à própria modernidade enquanto projeto de racionalização, sobretudo quando essa positividade se vê constituída a partir do desejo como mola propulsora da individualidade, como se nota nos poemas "O Passarinho Dela," "O Vôo Sobre as Igrejas," "Canção Para Ninar Mulher," no "Desdobramento de Adagilsa," entre outros.

Aqui importa sublinhar que a posição do sujeito drummondiano com a modernidade é uma posição ambígua. Se por um lado se reconhece a Morte de Deus, por outro lado, a exaltação extremada do elemento humano enquanto sujeito desejoso mina o próprio ideal racionalizador quando se tem em mente certa tradição do pensamento moderno ocidental que busca definir a superioridade da razão sobre o desejo como forma necessária para disciplinar o sujeito. ${ }^{13}$ A ambiguidade do sujeito drummondiano nasce exatamente a partir do

12. Ao tranformar a apologia do erótico em positividade, distancio-me aqui da tendência negativa da crítica, enraizada nos primeiros comentários de Mário de Andrade sobre a temática escrachadamente sexual de alguns dos poemas de Alguma poesia. O autor da Paulicéia condena todo sensualismo exarcebado, visível de Alguma poesia, por não ter conseguido o poeta ainda transformar o tema liricamente. Segundo ele, Drummond não teria conseguido sublimar o corpo poeticamente, de tal modo que essa subjetividade sensualizada seria assim um "desvio" da verdadeira subjetividade lírica drummondiana. ANDRADE, 1978. p. 70-71.

13. CASCARDI, 1992; CHAUí, 1990. p. 19-66. 
momento em que se propõe o corpo desejoso como parte constitutiva da subjetividade e não como uma ameaça a ela, como propõe Cascardi. ${ }^{14}$ Drummond estaria, por assim dizer, contrapondo ao discurso da modernidade de controle do desejo uma proposta de liberação do sujeito desejante como potencial. Assim vista, a atitude escolhida pelo sujeito constitui em si uma transgressão da ordem instituída, situando, ou distanciando o sujeito num espaço crítico dessa mesma realidade na qual ele se acha inserido, como revela o poema "Em Face dos Últimos Acontecimentos" ("Oh! sejamos pornográficos"). " Nesta reflexão, pode-se dizer que a apologia do desejo é a espinha dorsal da subjetividade lírica deste grupo de poemas de Brejo das Almas que se analisará. O tema sexual, de certo modo já insinuado nos poemas de tom niilista analisados anteriormente, aqui ganha acentuada relevância, como mostra o poema "O Vôo Sobre as Igrejas," que passo a analisar.

Em "O Vôo Sobre as Igrejas" a tentativa de afastamento do divino e aproximação do mundo terreno volta a ter lugar, contudo com uma ênfase maior no desejo sexual. "O Vôo Sobre as Igrejas" nos remete de certo modo a alguns poemas de Alguma poesia, cujo tema busca retratar as cidades históricas de Minas. Enquanto no livro anterior o poeta prioriza a descrição das cidades no seu aspecto físico, neste poema, em particular, a priorização constitui-se sobre a figura histórica do Aleijadinho, sobretudo do seu aspecto humano. Em "O Vôo Sobre as Igrejas", não escapa ao leitor a lembrança de "Romaria" da obra anterior, no entanto a impressão que se tem é que aqui há uma romaria muito particular, individualizada:

\footnotetext{
Vamos até à Matriz de Antonio Dias

onde repousa, pó sem esperança, pó sem lembrança, o Aleijadinho.

Vamos subindo em procissão a lenta ladeira.

Padres e anjos, santos e bispos nos acompanham

e tornam mais rica, tornam mais grave a romaria de assombração.
}

Um movimento interno no poema marca o distanciamento gradativo do sujeito lírico do seu objeto de contemplação. Há um corte no poema, a partir do qual se vislumbra um momento de revelação, onde o passado

14. CASCARDI, 1992. p. 231.

15. Ver FOUCAULT, 1984. 
vai se dissipando deixando entrever o presente, o real sem nenhuma mística, no momento em que o sujeito lírico vai deixando para trás a procissão:

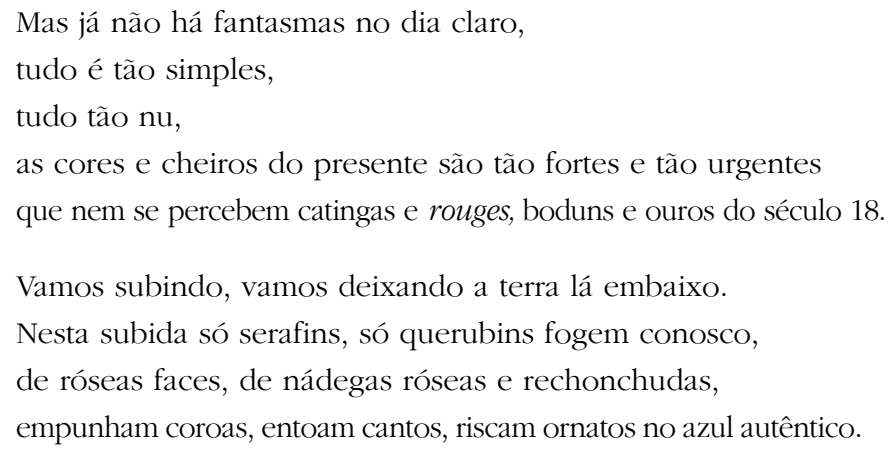

Gradativamente a descrição do ambiente sacro da procissão cede lugar à exaltação do elemento humano do Aleijadinho numa dessacralização da figura histórica. O sujeito lírico se distancia cada vez mais do ambiente religioso, e, paradoxalmente, o ideal de ascensão se dá de forma inversa: os anjos que o acompanham - salienta-se aqui o detalhe sexual na caracterização dos mesmos - passam a acompanhá-lo, não para o celestial mas sim para aquilo que é mais terreno, aquilo que é mais humano:

$$
\begin{aligned}
& \text { Este mulato de gênio } \\
& \text { lavou na pedra-sabão } \\
& \text { todos os nossos pecados } \\
& \text { as nossas luxúrias todas, } \\
& \text { esse tropel de desejos, } \\
& \text { essa ânsia de ir para o céu } \\
& \text { e de pecar mais na terra: } \\
& \text { este mulato de gênio } \\
& \text { subiu nas asas da fama, } \\
& \text { teve dinheiro, mulher, } \\
& \text { escravo, comida farta, } \\
& \text { teve também escorburto } \\
& \text { e morreu sem consolação. }
\end{aligned}
$$

O tom religioso inicial e de mistério vai desvelando a subjetividade nova que começa a constituir-se, e que de certa forma coincide com a própria subjetividade lírica que se vinha constituindo nos poemas analisados anteriormente, sobretudo na crise espiritual do sujeito. A subjetividade barroca 
do Aleijadinho reflete ao mesmo tempo a preocupação do sujeito lírico drummondiano tensionada entre o mundano e o espiritual, entre o desejo de conciliar o erótico com o espiritual.

$\mathrm{Na}$ construção da subjetividade da figura do Aleijadinho observase o mesmo desejo de saturação humana que já fora notado antes. Ou seja, a exaltação de tudo que seja excesso terreno, corporal, para com isto evidenciar a precariedade da condição humana: o abandono sem consolação, do qual não resta sequer a memória do corpo físico "já sem esperança / sem lembrança." Enquanto a exaltação do humano traz a marca do excesso, a precariedade caracteriza-se por um completo esvaziamento físico do sujeito representado, do qual não resta nem corpo nem memória histórica, senão - e apenas - a ilusão de uma suposta existência:

Era uma vez um Aleijadinho, não tinha dedo, não tinha mão, raiva e cinzel, lá isso tinha, era uma vez um Aleijadinho, era uma vez muitas igrejas com muitos paraísos e muitos infernos, $[\ldots]$

Ecos dessa aparente tensão de característica barroca, entre o espiritual e o mundano, na subjetividade lírica drummondiana ressoam também no poema "Castidade":

O perdido caminho, a perdida estrela que ficou lá longe, que ficou no alto, surgiu novamente, brilhou novamente como o caminho único, a solitária estrela.

Não me arrependo do pecado triste que sujou minha carne, suja toda carne. O caminho é tão claro, a estrela tão larga, os dois brilham tanto que me apago neles.

Mas certamente pecarei de novo (a estrela cala-se, o caminho perde-se), pecarei com humildade, serei vil e pobre, terei pena de mim e me perdoarei. 
De novo a estrela brilhará, mostrando o perdido caminho da perdida inocência.

E eu irei pequenino, irei luminoso conversando anjos que ninguém conversa.

Aqui uma vez mais evidencia-se o tema da sexualidade e da religiosidade, contudo com maior clareza a subjetividade se define a partir do princípio do desejo como força capaz de superar o religioso. Ecoa o peso cristão na consciência do sujeito no sentido de apagar da carne o sentido do desejo, na própria abnegação do corpo, numa prática típica da retórica cristã. Porém, na aparente confissão, desaparece o sentido de culpa, e o perdão advém da aceitação do desejo como parte dessa subjetividade. ${ }^{16}$ Diante disso, há um deciframento do sujeito lírico, o qual passa a se reconhecer desejante, encontrando no desejo a verdade do seu ser. Ainda que se reconheça certa abjeção ao corpo enquanto espaço do desejo, há no ato em si uma maior consideração, de tal forma que a transcendência possível encontra-se exatamente na aceitação da queda do sujeito, como revela a última estrofe: "E eu irei pequenino, irei luminoso / conversando anjos que ninguém conversa." ${ }^{17}$

Em princípio, o desejo em Drummond vai procurando visibilidade. Na sua matização a tendência maior dele é naturalizar-se, desaparecendo com isso a tensão interna entre o terreno e o espiritual. Contudo, persiste ainda uma outra forma de tensão interna: a dificuldade de se dominá-lo, como pode ser visto em "O Procurador do Amor," e a impossibilidade de se defini-lo discursivamente, como se vê no "Desdobramento de Adalgisa" - características naturais da dialética do próprio desejo.

\section{Conclusão}

Brejo das Almas organiza-se em torno de uma subjetividade lírica marcadamente em crise, nascida como um reflexo da modernidade, sobretudo quando observamos a constatação da precariedade da existência humana e da impossibilidade de transcendência. Ao enfatizar o elemento humano, o sujeito drummondiano encontra uma resposta possível à modernidade. Primeiro, exaltando-

16. FOUCAULT, 1984. p. 17.

17. Ver também o poema "Canção pra Ninar Mulher", do mesmo poemário. 
o, a ponto de intoxicar-se, advocando a sua autodestruição. Depois, reagindo contra o próprio ideal de racionalidade que por ventura busque disciplinar esse corpo, promovendo assim uma apologia do corpo gozoso a partir de uma poética do desejo. O livro na sua poética decadente, no seu subjetivismo exarcebado, não só revela a configuração de uma subjetividade trágica, mas contudo o impacto da modernidade sobre esse sujeito lírico. Rastrear em Brejo das Almas a relação de Drummond com o discurso da modernidade, a presença do elemento niilista, nascida da crença na precariedade existencial, aponta para a poética de Claro enigma (1951), onde, desaparecidas as tensões iniciais, toma lugar o lirismo de pura dimensão filosófica. O discurso do corpo que atravessa sua obra desde os primeiros versos, o desejo de intoxicação física pelo excesso, o lugar do desejo sexual na constituição da subjetividade fazem com que surja com naturalidade uma poética erótica, como a de O amor natural (1992), publicada postumamente.

\begin{abstract}
Carlos Drummond de Andrade's Brejo das Almas (1934) occupies a secondary place in Brazilian history of literature, seen most of the time as a simple extension of Drummond's initial book, Alguma poesia (1930). A careful analysis of the book reveals that Brejo das Almas has a very distinct poetic articulation which distinguishes it from his other works. This publication presents an open dialogue with the discourse of modernity, in particular with the philosophical discussions around the idea of the "Disenchantment of the World" and its impact on the poetic subject. My analysis shows how the intoxication and excesses of the physical body, along with the place of desire present in Drummond's book, serve as a poetic response to the loss of transcendence, or the idea of the "Death of God." I also show how Drummond's poetics indicates by itself not only a crisis in a conception of subjectivity, but also a crisis in modern culture, in a tragic view of modernity.
\end{abstract}

Key words: modern culture, poetry, crisis. 
Disponivel em: http://www.letras.ufmg.br/poslit

$$
\text { Referências Bibliográficas }
$$

ANDRADE, Carlos Drummond de. Obras completas. Rio de Janeiro: Aguillar, 1964.

ANDRADE, Mário de. In: BRAYNER, Sônia (Org.). Carlos Drummond de Andrade. Rio de Janeiro: Civilização Brasileira, 1978.

CANCLINI, Néstor García. Culturas híbridas: estrategias para entrar y salir de la modernidad. México: Grijalbo, 1989.

CASCARDI, Anthony J. The subject of modernity. Cambridge: Cambridge University Press, 1992.

CHAUI, Marilena. In: NOVAES, Adauto (Org.). O desejo. São Paulo: Companhia das Letras, 1990.

DELEUZE, Gilles; GUATTARI, Félix. Anti-Oedipus: capitalism and schizophrenia. Minneapolis: University of Minnesota Press, 1983.

FOUCAULT, Michael. História da sexualidade 1 - a vontade de saber. Rio de Janeiro: Graal, 1988.

História da sexualidade II: o uso dos prazeres. Rio de Janeiro: Graal, 1984.

FRIEDRICH, Hugo. Estrutura da lírica moderna. São Paulo: Duas Cidades, 1991.

HABERMAS, Jürgen. The philosophical discourse of modernity. [s.l.]: The MIT Press Cambridge, 1996.

KOJÈVE, Alexandre. Introduction to the reading of Hegel. Ithaca: Cornell University Press, 1993.

MARCUSE, Herbert. Eros and civilization: a philosophical inquire into Freud. Boston: Beacom Press, 1966.

NIETZSCHE, Friedrich. Nietzsche. São Paulo: Nova Cultural, 1987. v. I.

PAZ, Octavio. Los hijos del limo: del romanticismo a la vanguardia. Barcelona: Biblioteca del Bolsillo, 1993. 